\title{
Modulation of reversible self-assembling of dumbbell-shaped poly(ethylene glycol)s and $\beta$-cyclodextrins: precipitation and heat-induced supramolecular crosslinking
}

\begin{abstract}
Yuichiro Kobayashi ${ }^{1}$, Ryo Katoono ${ }^{1,2}$, Masayuki Yamaguchi ${ }^{1}$ and Nobuhiko Yui ${ }^{1,2}$
A series of dumbbell-shaped poly(ethylene glycol) (PEG) chains 1 attached to bulky end groups were prepared, and some of the chains formed supramolecular assemblies with $\beta$-cyclodextrin $(\beta-C D)$ and its multiple, ditopic and tetratopic, derivatives. The chains with proper end groups successfully allowed $\beta-C D$ to be trapped onto PEG through formation of hydrogen bonds at room temperature and higher. Mixing of the PEG chain and the ditopic supramolecular crosslinker in water at $40^{\circ} \mathrm{C}$ led to a change in solution property from viscous to elastic, accompanied by a significant increase in viscosity, whereas this change was not induced at room temperature. A supramolecular network formed only when the PEG chain was mixed with the tetratopic supramolecular crosslinker at $40{ }^{\circ} \mathrm{C}$. Once formed, the supramolecular crosslinking was maintained even after the system cooled down. Instead, dilution and shaking at room temperature resulted in a return to a solution with low viscosity. These assemblies and dissociations were affected by the end groups of 1 .
\end{abstract}

Polymer Journal (2011) 43, 893-900; doi:10.1038/pj.2011.71; published online 3 August 2011

Keywords: $\beta$-cyclodextrin; poly(ethylene glycol); pseudopolyrotaxane; supramolecular crosslinking; viscoelastic properties; viscosity

\section{INTRODUCTION}

One of the greatest findings in the 1990s was the self-assembly of cyclic molecules onto a linear polymeric chain, represented by $\alpha$-cyclodextrin $(\alpha-\mathrm{CD})$ onto poly(ethylene glycol) $(\mathrm{PEG})^{1,2}$ and $\beta$-cyclodextrin $(\beta-\mathrm{CD})$ onto poly(propylene glycol), ${ }^{3,4}$ leading to the development of supramolecular materials based on cyclodextrins ${ }^{5-8}$ and others. ${ }^{9,10}$ In the assembly, CD molecules formed intermolecular hydrogen bonds $s^{2,4,6,7}$ with each other to stay on the chain while threading and dethreading were competing, and finally a supramolecular assembly called pseudopolyrotaxane was obtained as a kinetic product. As a matter of course, some thermodynamic advantages accompanied this process, such as enthalpic gain on forming hydrogen bonds, ${ }^{6}$ and total entropic changes on assembly of the components, as well as desolvation. It seems that PEG and poly(propylene glycol) chains provided a suitable guide for $\alpha$-CD and $\beta$-CD to fill the size-matched cavity and align cooperatively through formation of hydrogen bonds. In recent years, Takata et al. reported an excellent synthetic approach for yielding pseudopolyrotaxanes based on self-assembly of modified CD molecules onto a linear polymeric chain without relying on forming hydrogen bonds, but using heterogeneous systems in which permethylated $\alpha$-CD and poly(tetrahydrofuran) or PEG were used in hydrocarbon solvents ${ }^{11}$ as well as in water. ${ }^{12}$ Even though the initial a
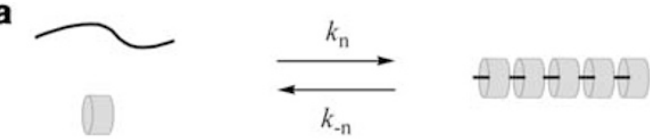

b
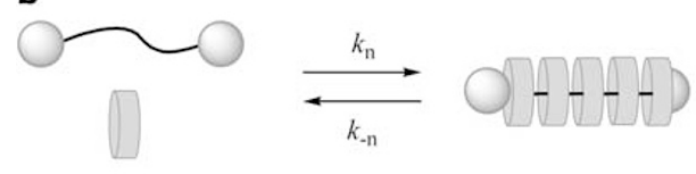

C
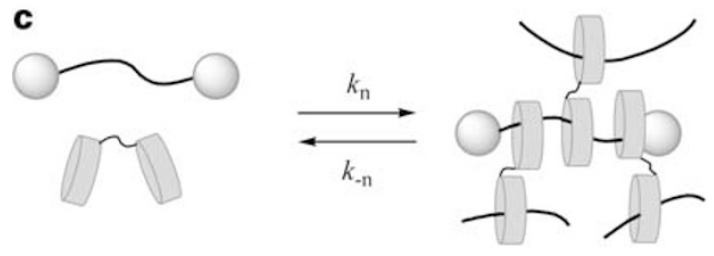

Scheme 1 (a) Pseudopolyrotaxane formation between size-matched cyclic and linear components, (b) pseudopolyrotaxane formation between sizemismatched cyclic and dumbbell-shaped linear components and (c) supramolecular crosslinking based on pseudopolyrotaxane formation between size-mismatched crosslinked cyclic and dumbbell-shaped linear components.

${ }^{1}$ School of Materials Science, Japan Advanced Institute of Science and Technology, Nomi, Ishikawa, Japan and 2JST, CREST, Chiyoda-ku, Tokyo, Japan Correspondence: Dr R Katoono, School of Materials Science, Japan Advanced Institute of Science and Technology, 1-1 Asahidai, Nomi, Ishikawa 923-1292, Japan. E-mail: katoono@jaist.ac.jp

Received 23 March 2011; revised 11 May 2011; accepted 10 June 2011; published online 3 August 2011 


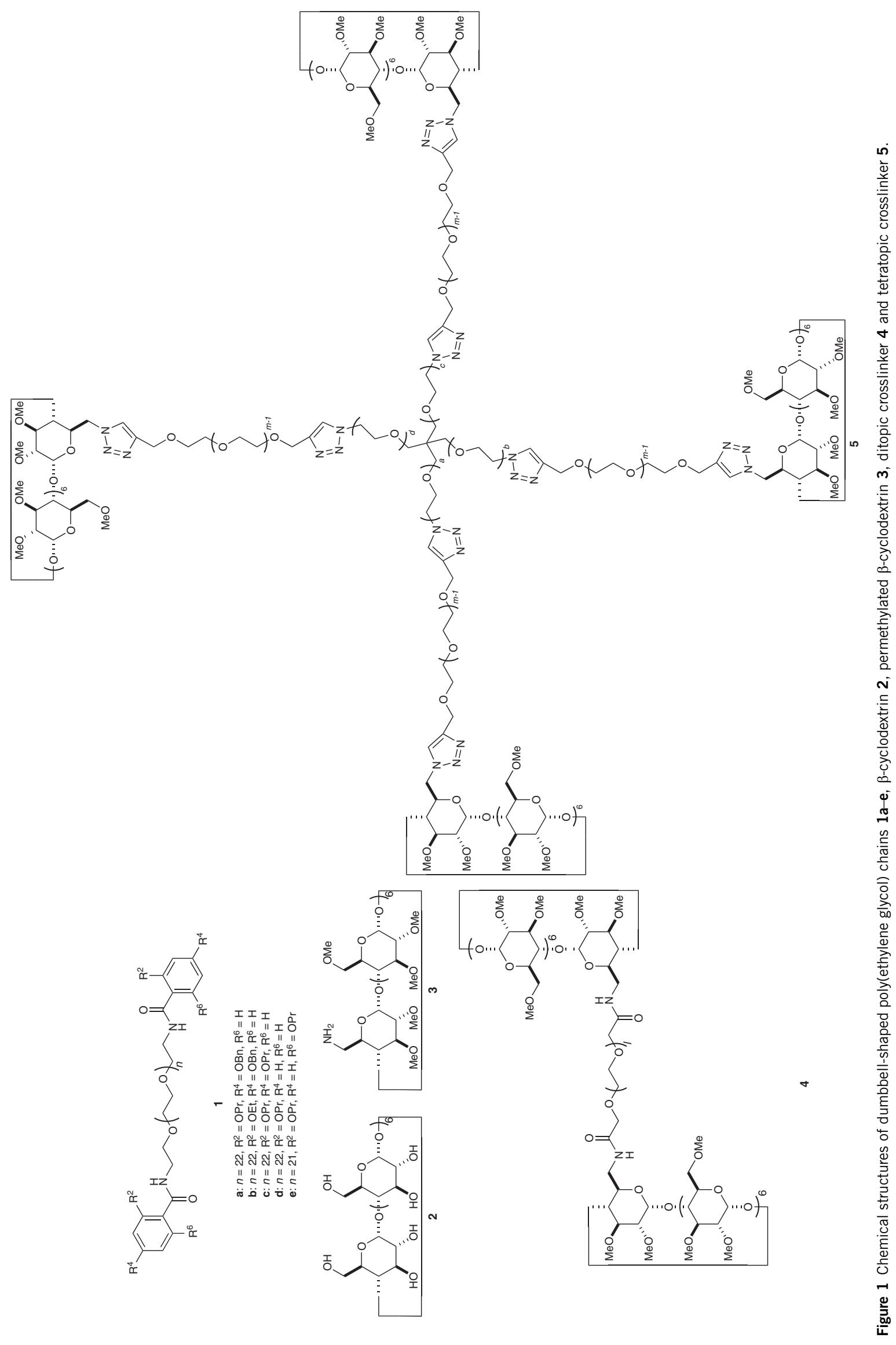




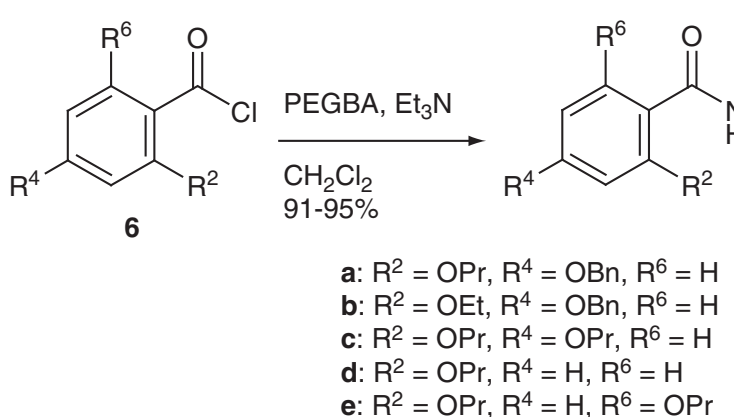

Scheme 2 Preparation of dumbbell-shaped poly(ethylene glycol) chains 1. PEGBA, poly(ethylene glycol) bis(2-aminoethyl) ether
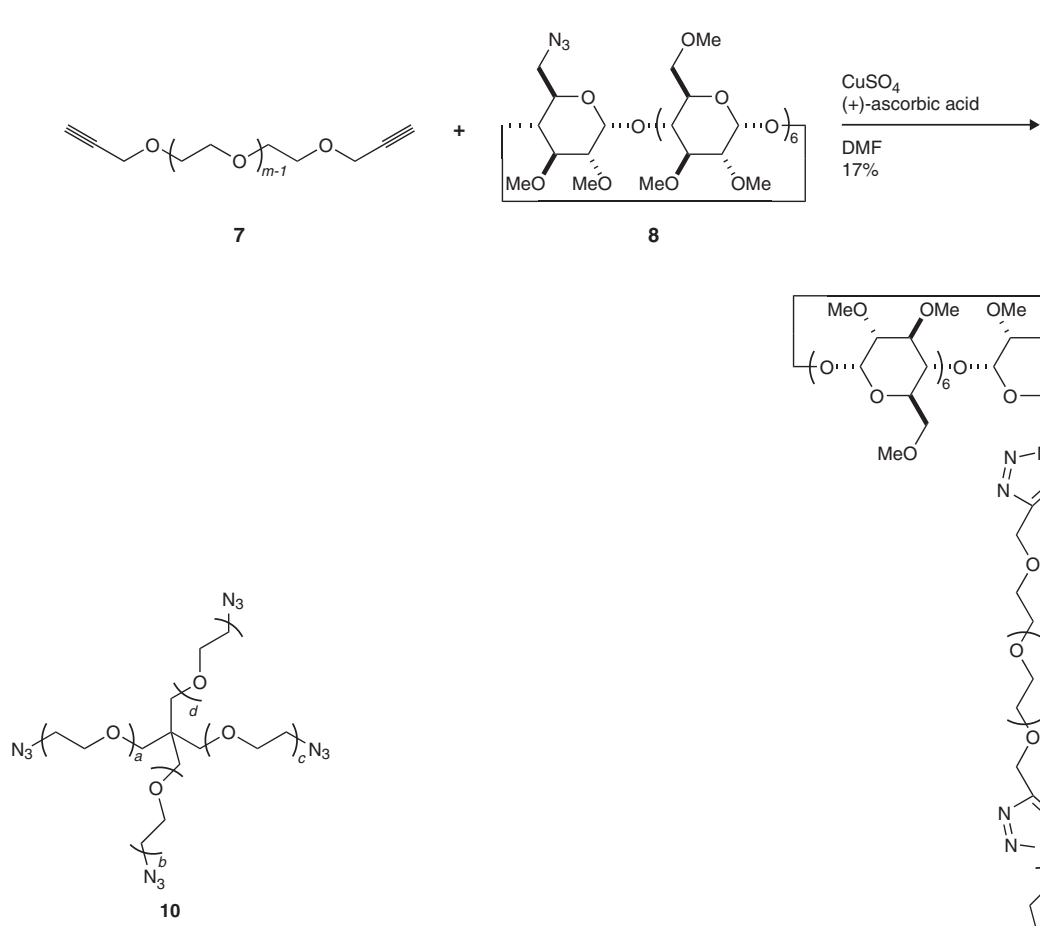

$\mathrm{CuSO}_{4}$

(+)-ascorbic acid
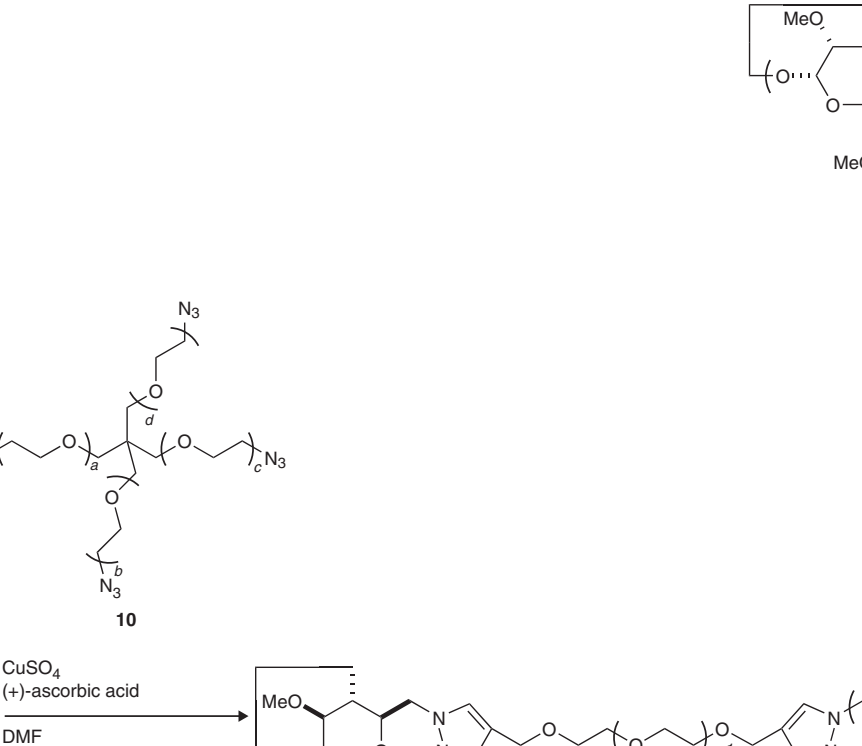

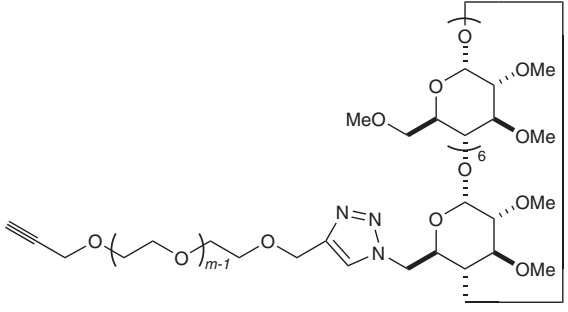<smiles></smiles>

1 


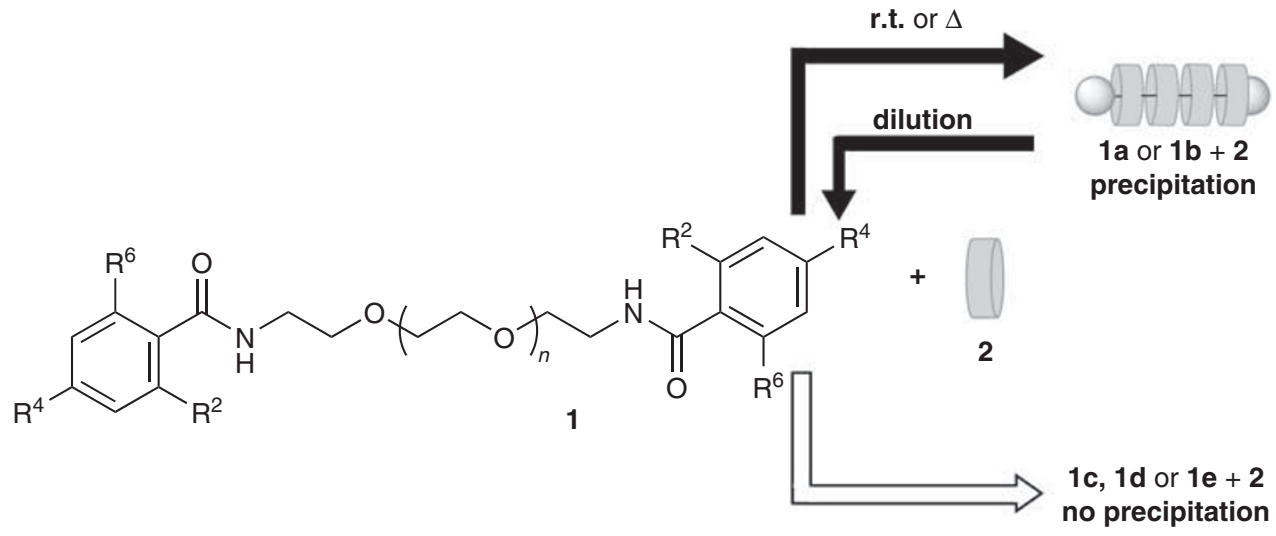

Scheme 4 Mixing of $\mathbf{1}$ with $\mathbf{2}$ in water leading to precipitation (1a, $\mathbf{1 b})$ at room temperature (r.t.) or elevated temperature, or no precipitation (1c, $\mathbf{1 d}$ and $1 \mathrm{e})$, and dissociation by dilution.

Table 1 Conditions (concentration and temperature) for complexation of $1 \mathrm{a}, 1 \mathrm{~b}$ or PEGBA with 2,3 or $\alpha-\mathrm{CD}$, ${ }^{\mathrm{a}}$ and results (time for precipitation, ratio ${ }^{\mathrm{b}}$ of PEG to $\mathrm{CD}$ in an isolated solid and yield ${ }^{\mathrm{c}}$ )

\begin{tabular}{|c|c|c|c|c|c|c|c|}
\hline \multirow[b]{2}{*}{$P E G$} & \multirow[b]{2}{*}{$C D$} & \multicolumn{2}{|c|}{ Concentration (mм) } & \multirow[b]{2}{*}{ Temperature $\left({ }^{\circ} \mathrm{C}\right)$} & \multirow[b]{2}{*}{ Time (day) } & \multirow[b]{2}{*}{ Ratio $^{\mathrm{b}}$ (PEG:CD) } & \multirow[b]{2}{*}{ Yield $(\%)$} \\
\hline & & $P E G$ & $C D$ & & & & \\
\hline \multirow[t]{4}{*}{$1 a$} & 2 & 1.3 & 15 & rt & 10 & $1: 10$ & 29 \\
\hline & & 4.8 & 57 & 60 & 4 & $1: 10$ & $28^{d}$ \\
\hline & 3 & 64 & $7.1 \times 10^{2}$ & $\mathrm{rt}$ & - & - & 0 \\
\hline & & 64 & $7.1 \times 10^{2}$ & 60 & - & - & 0 \\
\hline \multirow[t]{2}{*}{$1 \mathrm{~b}$} & 2 & 1.3 & 15 & $\mathrm{rt}$ & 5 & $1: 10$ & 23 \\
\hline & & 4.8 & 55 & 60 & 2 & $1: 10$ & $20^{d}$ \\
\hline \multirow[t]{2}{*}{ PEGBA } & 2 & 1.3 & 15 & rt & - & - & 0 \\
\hline & $\alpha-C D$ & 13 & $1.4 \times 10^{2}$ & rt & $<1$ & $-(1: 10)$ & $0(92)$ \\
\hline
\end{tabular}

Abbreviations: $\alpha$-CD, $\alpha$-cyclodextrin; PEG, poly(ethylene glycol); PEGBA, poly(ethylene glycol) bis(2-aminoethyl) ether; rt, room temperature.

aPEG was added to a solution of $C D$ in water, and the mixture was stirred. A solid was obtained by filtration, followed by washing with 10 times the amount of water.

${ }^{\mathrm{b}}$ The ratio was determined by the ${ }^{1} \mathrm{H}$ nuclear magnetic resonance spectrum of an isolated solid measured in DMSO- $d_{6}$, based on an assumption that the average number of repeating units ( $n$ ) was maintained in the solid.

'The yield was calculated based on PEG with the same assumption as above. The number in parenthesis is the ratio or yield obtained when the solid was washed with a small amount of water, as reported in references 1 and 2, where PEG $\left(M_{W}=1000\right)$ was used instead of PEGBA.

${ }^{\mathrm{d}}$ These solids were used to measure powder X-ray diffraction.

Table 2 Conditions (concentration, ${ }^{\text {a }}$ temperature and time) for mixing of 1a-e or PEGBA with 4 or 5, and zero-shear viscosity

\begin{tabular}{|c|c|c|c|c|c|c|}
\hline \multirow[b]{2}{*}{ PEG } & \multirow[b]{2}{*}{ Crosslinker } & \multicolumn{2}{|c|}{ Concentration ${ }^{\mathrm{a}}(\mathrm{mm})$} & \multirow[b]{2}{*}{ Temperature $\left({ }^{\circ} \mathrm{C}\right)$} & \multirow[b]{2}{*}{ Time (day) } & \multirow[b]{2}{*}{ Zero-shear viscosity (Pa•s) } \\
\hline & & $P E G$ & Crosslinker & & & \\
\hline \multirow[t]{5}{*}{$1 \mathrm{a}$} & 4 & 46 & $2.5 \times 10^{2}$ & $\mathrm{rt}$ & 10 & $-\mathrm{b}$ \\
\hline & & & & 40 & $6 / 8$ & $1.7 \times 10^{5} / \mathrm{C}^{\mathrm{c}}$ \\
\hline & & 31 & $1.6 \times 10^{2}$ & 40 & 8 & $2.1 \times 10^{3}$ \\
\hline & & 20 & $1.0 \times 10^{2}$ & 40 & 8 & $-{ }^{b}$ \\
\hline & 5 & 19 & 52 & 40 & 3 & $-^{c}$ \\
\hline \multirow[t]{4}{*}{$1 b$} & 4 & 46 & $2.5 \times 10^{2}$ & $\mathrm{rt}$ & 10 & $-\mathrm{b}$ \\
\hline & & & & 40 & $3 / 6$ & $2.4 \times 10^{2} /-^{c}$ \\
\hline & & 31 & $1.6 \times 10^{2}$ & 40 & 8 & $1.9 \times 10^{2}$ \\
\hline & & 20 & $1.0 \times 10^{2}$ & 40 & 8 & $-\mathrm{b}$ \\
\hline \multirow[t]{5}{*}{$1 \mathrm{c}$} & 4 & 46 & $2.4 \times 10^{2}$ & rt & 10 & $-\mathrm{b}$ \\
\hline & & & & 40 & 8 & $9.7 \times 10^{3}$ \\
\hline & & 31 & $1.6 \times 10^{2}$ & 40 & 8 & $-\mathrm{b}$ \\
\hline & & 20 & $1.0 \times 10^{2}$ & 40 & 8 & $-\mathrm{b}$ \\
\hline & 5 & 19 & 52 & 40 & 3 & $8.8 \times 10$ \\
\hline $1 d$ & 4 & 46 & $2.5 \times 10^{2}$ & 40 & 6 & $-b$ \\
\hline $1 e$ & 4 & 46 & $2.5 \times 10^{2}$ & 40 & 6 & $-\mathrm{b}$ \\
\hline PEGBA & 4 & 46 & $2.5 \times 10^{2}$ & 40 & 8 & $-b$ \\
\hline
\end{tabular}

Abbreviations: PEG, poly(ethylene glycol); PEGBA, poly(ethylene glycol) bis(2-aminoethyl) ether; rt, room temperature.

aThe ratio of PEG to methylated $\beta-C D$ component in $4 / 5$ is $1: 11$ in all solutions.

bNot determined or insignificant at most on the order of $\sim 10^{0} \mathrm{~Pa} \bullet$ s.

cNot determined because of the disappearance of the terminal region. 
1:1 complex is not necessarily preferred to form, threading occurs sequentially and the complexation reaction proceeds because dethreading is retarded through kinetic and/or thermodynamic stabilization of intermediary complexes in a cooperative manner, which seems unfavorable for a size-mismatched combination (Scheme 1a). ${ }^{2}$ Each cyclic molecule enters on threading and leaves at the end of a chain. Setting up a barrier at each end of a chain affects both entering and leaving, ${ }^{6,7}$ and brings about changes in the ratio of $k_{\mathrm{n}} / k_{-\mathrm{n}}$. A precise barrier ideally allows a cyclic molecule to remain on any chain, instead of relying on specific combinations of cyclic and linear components with size adequacy (Scheme 1b). In addition, cyclic molecules would stay on chains cooperatively when they were crosslinked by a spacer, leading to a supramolecular network through the pseudopolyrotaxane formation (Scheme 1c). ${ }^{13-17}$

Here we report the roles of barriers at the ends of a chain, and crosslinking of cyclic molecules in self-assembly of size-mismatched components, PEG and $\beta$-CD. ${ }^{17-19}$ We investigated systematically the pseudopolyrotaxane formation of a series of dumbbell-shaped PEG chains 1a-e with native $\beta$-CD 2 and its permethylated derivative $3^{20}$ (Scheme $1 \mathrm{~b}$ and Figure 1). Two crosslinked $\beta$-CD derivatives, ditopic $4^{17}$ and tetratopic 5, were used to form a supramolecular network on mixing with 1 in water (Scheme 1c and Figure 1).

\section{EXPERIMENTAL PROCEDURE}

\section{Materials}

Poly(ethylene glycol)s (average $M_{\mathrm{n}}: 380-420$ and 950-1050) were purchased from Aldrich Co. Ltd. (St Louis, MO, USA), and used as a starting material to prepare PEG bis(prop-2-ynyl) ether 7 (matrix-assisted laser desorption/ionization time-of-flight mass spectrometry $m / z 513\left([\mathrm{M}(m=9)+\mathrm{Na}]^{+}, \mathrm{BP}\right),{ }^{21}$ and PEG bis(2-aminoethyl) ether (matrix-assisted laser desorption/ionization timeof-flight MS $m / z 1096\left([\mathrm{M}(n=22)+\mathrm{Na}]^{+}, \mathrm{BP}\right) .^{22}$ Pentaerythritol ethoxylate 16 (average $M_{\mathrm{n}}$ : 797) was purchased from Aldrich Co. Ltd., and derived to quadruply-azidated 10. Heptakis(2,3-di-O-methyl)-hexakis(6-O-methyl)-6monodeoxy-6-monoazido- $\beta$-CD $\mathbf{8}$ and heptakis(2,3-di-O-methyl)-hexakis (6-O-methyl)-6-monodeoxy-6-monoamino- $\beta$-CD 3 were prepared according to literature. ${ }^{20}$ Synthetic procedures and spectral data of new compounds $(\mathbf{1}, \mathbf{5}$, $9,10,12,13$ and 17), and experimental details of complexation study are described in Supporting Information.

\section{Measurements}

The frequency dependence of the oscillatory shear moduli, such as shear storage modulus $G^{\prime}$ and loss modulus $G^{\prime \prime}$ in aqueous solutions, was measured by a cone-and-plate rheometer (MR500, UBM, Kyoto, Japan) at $25 \pm 1{ }^{\circ} \mathrm{C}$. The cone angle was $5^{\circ}$ and the diameter was $25 \mathrm{~mm}$.

X-ray diffraction measurement was performed with a powder diffractometer (RINT2000, Rigaku, Tokyo, Japan) using graphite-monochromatized $\mathrm{CuK} \alpha$ radiation $(\lambda=1.542 \AA)$.

Matrix-assisted laser desorption/ionization time-of-flight mass spectra were recorded in the reflector mode on a mass spectrometer (Voyager DE RP, PerSeptive Biosystems, Framingham, MA, USA) using a nitrogen laser $(337 \mathrm{~nm})$ and an accelerating potential of $25 \mathrm{kV} . \alpha$-Cyano-4-hydroxycinnamic acid was used as a matrix.

\section{RESULTS AND DISCUSSION}

Preparation of dumbbell-shaped PEG chains 1 and supramolecular crosslinkers, ditopic 4 and tetratopic 5

The dumbbell-shaped PEG chains $\mathbf{1 a}-\mathbf{e}$ were prepared by a reaction of PEG (average $n=22$ ) bis(2-aminoethyl) ether with corresponding benzoyl chlorides 6 that have one or two alkyloxy group(s) at 2-, 4or 6-position (Scheme 2). The ditopic crosslinker 4 was prepared by attachment of monoaminated permethylated $\beta-C D$ to each end of PEG (average $l=7$ ) bis(carboxymethyl) ether through a condensation
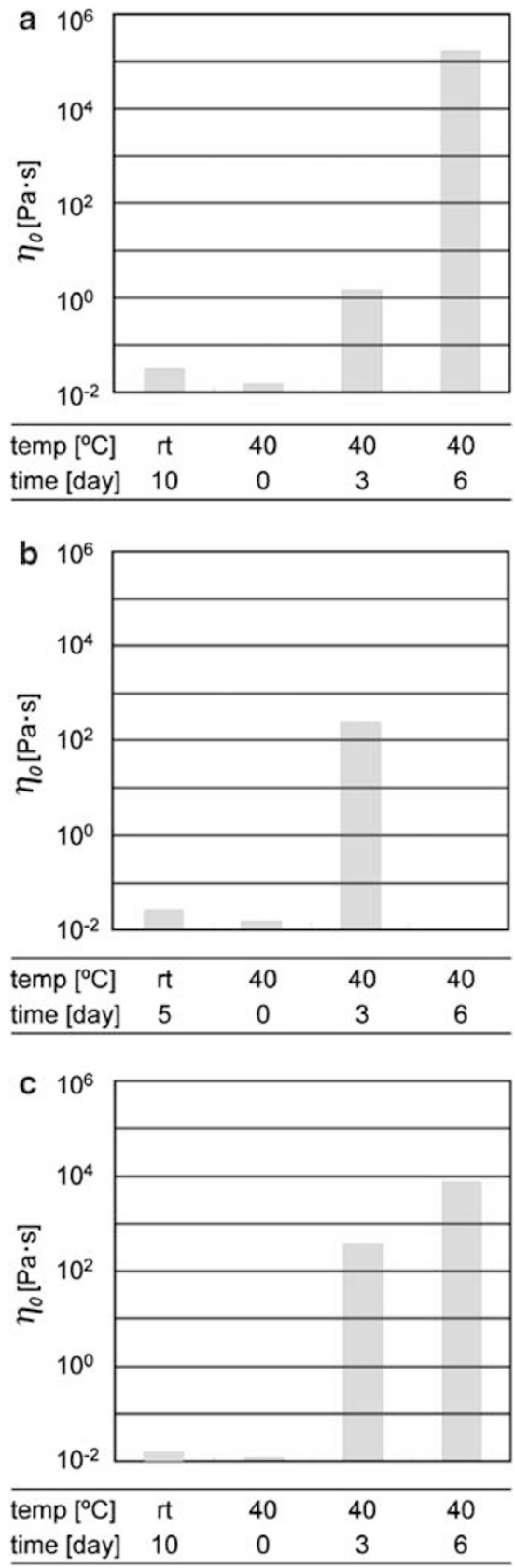

Figure 2 Zero-shear viscosities $\left(\eta_{0}\right)$ of aqueous solution of (a) dumbbellshaped PEG 1a, (b) 1 b and (c) 1c ( $46 \mathrm{~mm})$ in the presence of ditopic crosslinker $4(0.25 \mathrm{~m})$, determined by measurement of complex viscosities $\left(\eta^{*}\right)$ at $25 \pm 1{ }^{\circ} \mathrm{C}$, followed by calculation according to the equation $\eta_{0} \equiv \lim \omega \rightarrow O\left(G^{\prime \prime} / \omega\right)$. For a solution of 1 b stirred at $40^{\circ} \mathrm{C}$ for 6 days (Figure $2 \mathrm{~b}$ ), the viscosity was not determined due to disappearance of the terminal region.

reaction. ${ }^{17}$ The tetratopic crosslinker $\mathbf{5}$ was prepared by repeated 1,3-dipolar cycloaddition reactions ${ }^{23,24}$ of monoazidated permethylated $\beta$-CD $\mathbf{8}^{20}$ and quadruply-azidated pentaerythritol ethoxylate $\mathbf{1 0}$ (average $a+b+c+d=15$ ) at the respective ends of PEG (average $m=9$ ) bis(prop-2-ynyl) ether 7 (Scheme 3).

Inclusion complexation of dumbbell-shaped 1 with $\beta$-CD 2 Complexation of the dumbbell-shaped PEG chains 1 with native $\beta$-CD 2 was first investigated by mixing in water at room temperature 


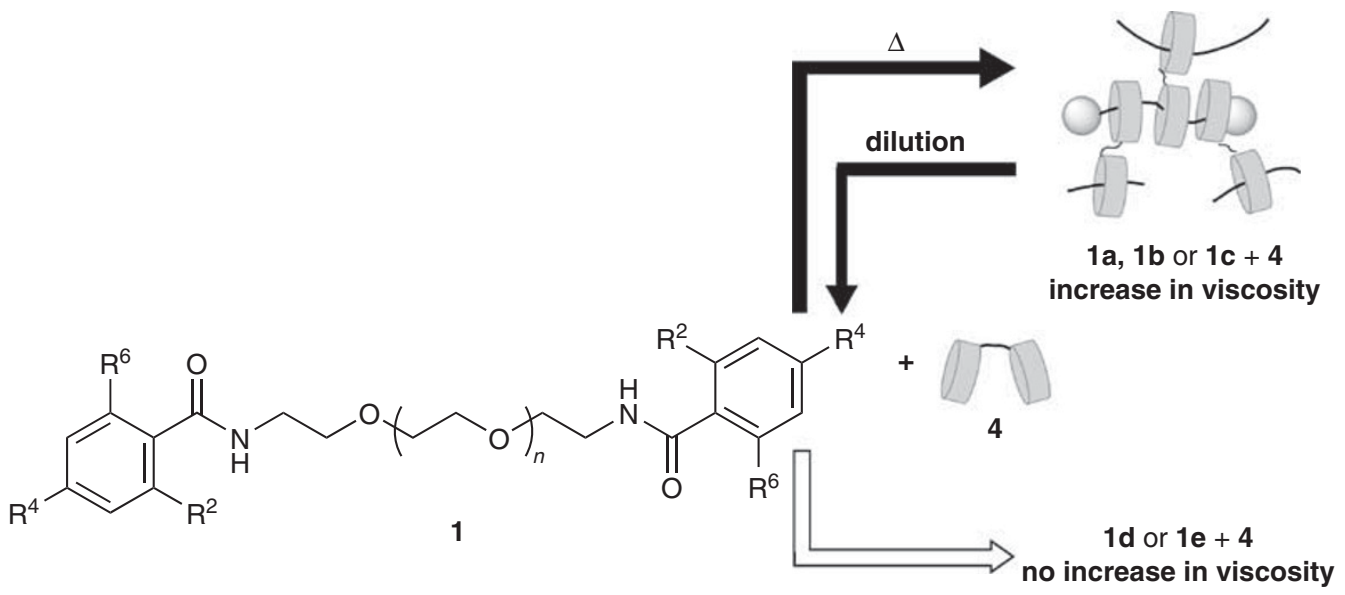

Scheme 5 Mixing of 1 with 4 in water leading to increase in viscosity only at elevated temperature (1a, $\mathbf{1 b}$ and $\mathbf{1 c})$ or no increase (1d, 1e), and dissociation by dilution.
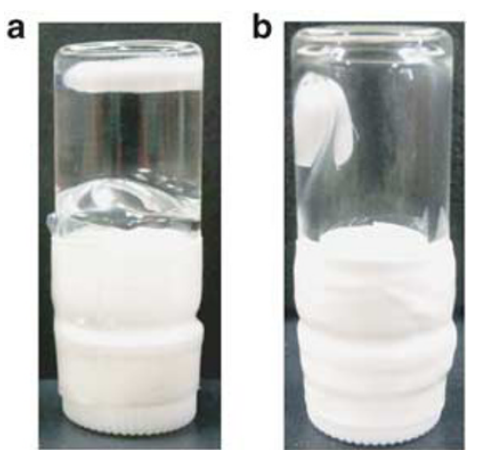

Figure 3 Photographs of aqueous solution of dumbbell-shaped poly(ethylene glycol) 1a (46 mm) and ditopic crosslinker $4(0.25 \mathrm{~m})$, stirred at $40^{\circ} \mathrm{C}$ for 8 days, followed by inverting and standing for (a) 0 and (b) $24 \mathrm{~h}$.

and at $60{ }^{\circ} \mathrm{C}$ (Scheme 4 and Table 1). Mixing of 1a with 2 in water at room temperature for 10 days successfully gave a white solid. The ${ }^{1} \mathrm{H}$ nuclear magnetic resonance spectrum of the isolated solid measured in DMSO- $d_{6}$ indicated a simple integration of $1 \mathbf{a}$ and 2 at a ratio of 1 to 10. An indistinguishable solid was given on mixing at $60^{\circ} \mathrm{C}$ from the solid formed at room temperature. The powder X-ray diffraction pattern for the solid of $1 \mathbf{a}$ and $\mathbf{2}$ is quite similar to that of $\beta-C D$ itself., ${ }^{4,25}$ Mixing of $\mathbf{1 a}$ with permethylated $\mathbf{3}$ failed to produce any solid, and just gave a transparent solution at both room temperature and $60^{\circ} \mathrm{C}$. If we consider the hydrophobic inherence in 1a, whose solution is turbid in water at any temperature, the solubilization would be accounted for by assuming inclusion complexation with 3 at least at the end of $1 \mathbf{a}^{17}$ It would be difficult to judge whether the methylated $\beta-C D$ was trapped onto 1a or not from only the appearance due to high water solubility of $3 .^{18}$ Similar results were obtained from mixing of $\mathbf{1 b}$ with $\mathbf{2}$ or $\mathbf{3}$ qualitatively, in terms of precipitation or solubilization (Table 1). Note that mixing at $60{ }^{\circ} \mathrm{C}$ accelerated precipitation, ${ }^{7}$ and gave an indistinguishable solid in a similar yield to that given at room temperature. A longer time was required for precipitation that resulted in a higher yield for $\mathbf{1 a}\left[R^{2}=\mathrm{OPr}, R^{4}=\mathrm{OBn}\right]$ than for $\mathbf{1 b}\left[R^{2}=\mathrm{OEt}, R^{4}=\mathrm{Obn}\right.$ ] (Table 1 ). All solids obtained here dissolved in DMSO or in an excessive amount of water, indicating formation of hydrogen bonds as commonly seen in an inclusion complex of native cyclodextrins. ${ }^{1-4,26,27}$ As previously reported, the results of mixing PEG bis(2-aminoethyl) ether, which has no bulkiness at the ends, with $\alpha-C^{1,2}$ and $\beta-C D^{3,4}$ are also listed in Table 1 for reference. As in the case of the mixing of $1 \mathrm{a}$ with 3 , no precipitates were formed from a transparent solution of $1 \mathrm{c}\left[R^{2}=\mathrm{OPr}, R^{4}=\mathrm{OPr}\right]$, 1d $\left[R^{2}=\mathrm{OPr}\right]$ or $1 \mathrm{e}\left[R^{2}=\mathrm{OPr}, R^{6}=\mathrm{OPr}\right]$ in the presence of $\mathbf{2}$ at any temperature (Scheme 4).

\section{Supramolecular crosslinking of dumbbell-shaped 1 with ditopic 4 and tetratopic 5}

Complexation of dumbbell-shaped 1 with the ditopic crosslinker 4 was then investigated in terms of the zero-shear viscosity $\left(\eta_{0}\right)$ of a transparent solution in water under several conditions (Table 2). If each of the two permethylated $\beta-\mathrm{CD}$ molecules in $\mathbf{4}$ is discretely assembled onto a chain, and the supramolecularly crosslinked complexes are stable, this will lead to an increase in viscosity. ${ }^{28}$ Mixing of $\mathbf{1 a} / \mathbf{b}(46 \mathrm{~mm})$ with $4(0.25 \mathrm{M})$ at room temperature for $10 / 5$ days led to no change in viscosity (Figures $2 \mathrm{a}$ and $\mathrm{b}$ ), but the solution appeared to be similar to a solution of $\mathbf{1 a}$ and permethylated 3. Alternatively, heating these systems induced increases in viscosity over time, which attained an order of $10^{5} \mathrm{~Pa} \bullet$ after periods of 6 days for $1 \mathrm{a}\left[R^{2}=\mathrm{OPr}\right.$, $R^{4}=\mathrm{OBn}$ ], and 3 days for $\mathbf{1 b}\left[R^{2}=\mathrm{OEt}, R^{4}=\mathrm{OBn}\right.$ ) (Scheme 5 and Figures $2 \mathrm{a}$ and $\mathrm{b}$ ). If the increase in viscosity was achieved through inclusion complexation with 4 only at the ends of $\mathbf{1 a} / \mathbf{b}$, the solution viscosity would decrease with heating. ${ }^{29-32}$ It is noteworthy that a gradual increase in viscosity was also found in a solution of 1c $(46 \mathrm{~mm})\left[R^{2}=\mathrm{OPr}, R^{4}=\mathrm{OPr}\right]$ in the presence of $4(0.24 \mathrm{M})$ at $40^{\circ} \mathrm{C}$ (Scheme 5 and Figure 2c), if we consider the failure of precipitation to occur on mixing of $1 \mathrm{c}$ with native $\beta-\mathrm{CD} 2$ at any temperature (Scheme 4). The viscosity did not increase at room temperature as in the case of mixing of $\mathbf{1 a}$ or $\mathbf{1} \mathbf{b}$ with $\mathbf{4}$ (Figure 2). Also note that these increased viscosities still remained for weeks after the system cooled down, and returned to solutions with low viscosity $\left(\sim 10^{-2}\right.$ Pa॰s) by triple dilution with water followed by shaking at room temperature for 5 days for 1a, for 2 days for $\mathbf{1 b}$ and within 1 day for $\mathbf{1 c}$ (Scheme 5). These results indicate that the pseudopolyrotaxanes were formed on heating, ${ }^{18}$ and were kinetically stable during the supramolecular crosslinking. It is important for the system to be heated to form an assembly through the supramolecular crosslinking, although slipping on/off is allowed even at room temperature (see above). The values of $\eta_{0}$ measured at low concentrations $([\mathbf{1 a}-\mathbf{c}]<20 \mathrm{~mm},[\mathbf{4}]<0.10 \mathrm{M})$ were 

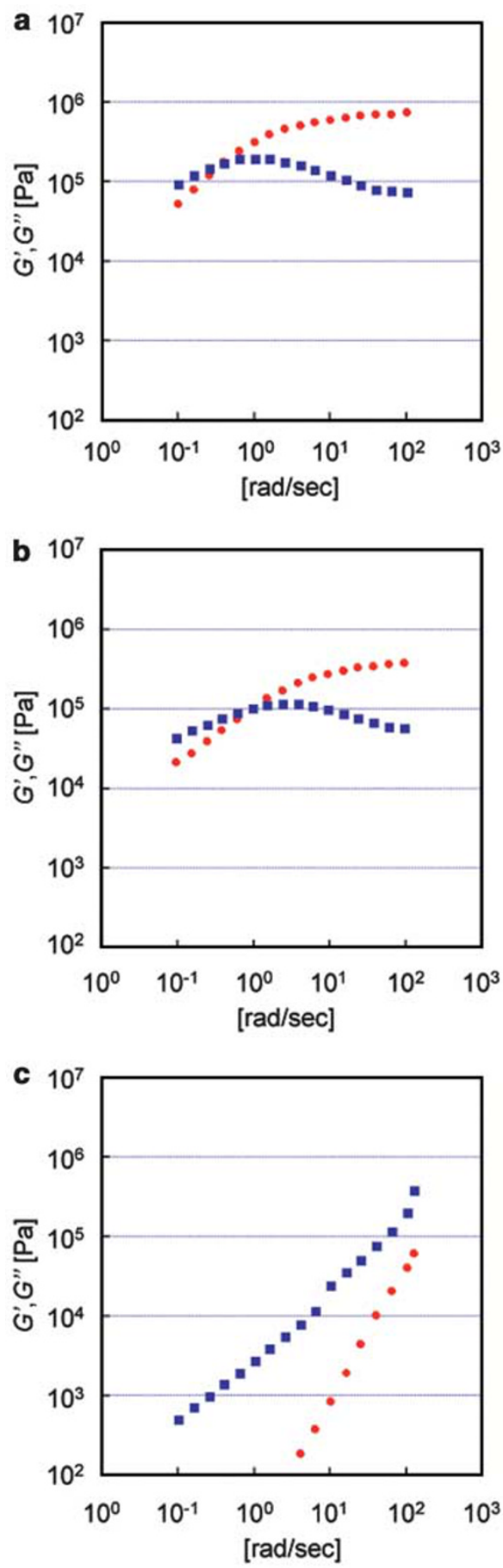

Figure 4 Frequency dependency of storage modulus ( $G^{\prime}$, red circle) and loss modulus ( $G^{\prime \prime}$, blue square) of aqueous solution of (a) dumbbell-shaped poly(ethylene glycol) $1 \mathrm{a}$ in the presence of ditopic crosslinker $\mathbf{4}$ stirred at $40^{\circ} \mathrm{C}$ for 8 days, (b) $1 \mathrm{~b}$ in the presence of 4 stirred at $40^{\circ} \mathrm{C}$ for 6 days and (c) $1 \mathrm{c}$ in the presence of 4 stirred at $40^{\circ} \mathrm{C}$ for 8 days $([1]=46 \mathrm{~mm}$, [4] $=0.25 \mathrm{M}$ ), measured at $25 \pm 1^{\circ} \mathrm{C}$.

on the order of $\sim 10^{0}$ Paøs. The values increased with concentration as

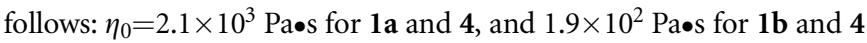
$([\mathbf{1 a}],[\mathbf{1 b}]=31 \mathrm{~mm},[\mathbf{4}]=0.16 \mathrm{M})$ and so on, measured after maintaining a solution at $40{ }^{\circ} \mathrm{C}$ for 8 days. Solutions with so high concentrations are no longer allowed to measure nuclear magnetic resonance
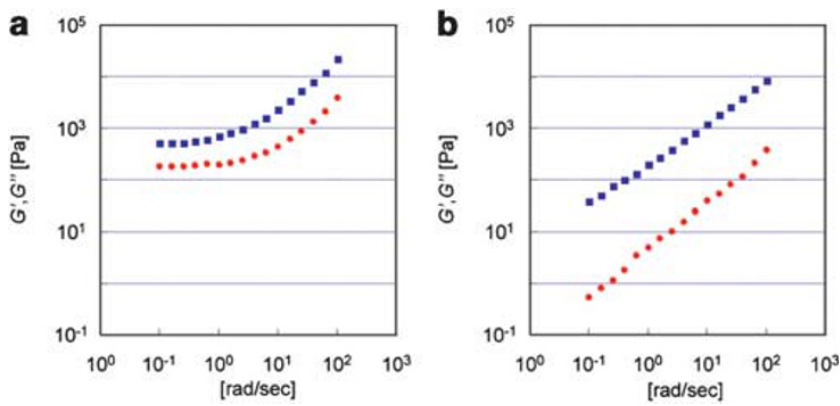

Figure 5 Frequency dependency of storage modulus ( $G^{\prime}$, red circle) and loss modulus ( $G^{\prime \prime}$, blue square) of aqueous solution of (a) dumbbell-shaped poly(ethylene glycol) $\mathbf{1 a}$ in the presence of tetratopic crosslinker $\mathbf{5}$, and (b) $1 \mathrm{c}$ in the presence of 5 stirred at $40^{\circ} \mathrm{C}$ for 3 days $([1]=19 \mathrm{~mm}$, [5] $=52 \mathrm{~mm})$, measured at $25 \pm 1{ }^{\circ} \mathrm{C}$. In a solution of $1 \mathrm{a} / \mathrm{c}(19 \mathrm{~mm})$ itself or 5 (52 mm) itself, the values of $G^{\prime}$ and $G^{\prime \prime}$ were on the order of $\sim 10^{-2} \mathrm{~Pa}$, measured under the same conditions.

with suitable quality. In a transparent solution of $\mathbf{1 d}, \mathbf{1 e}$ or PEG bis(2-aminoethyl) ether in the presence of 4 , the viscosity remained on an order of $10^{-2}$ Paıs under any conditions (Scheme 5). These results are also summarized in Table 2.

A solution with increased viscosity becomes harder to stir. In fact, a stirring bar stopped on the 8 th/6th day from the time a solution of $1 \mathrm{a} /$ b and 4 was heated to $40^{\circ} \mathrm{C}$, whereas it had been continuing in a solution of $1 \mathrm{c}$ and 4 for 8 days at that temperature. As shown in Figure 3, the solution of $1 \mathbf{a}$ and $\mathbf{4}$ appears deceptively something similar to a gel in the photograph (Figure 3a), and is fluent in the long term ( $\sim 2$ days; Figure $3 b)$. We describe these macroscopic observations through dynamic viscoelastic measurement. ${ }^{33}$ For the solution of $\mathbf{1 a} / \mathbf{b}$ and 4 stirred at $40^{\circ} \mathrm{C}$ for $8 / 6$ days, we can find the rubbery region in high frequency, indicating that the solution property changed from viscous to elastic (Figures $4 \mathrm{a}$ and $\mathrm{b}$ ). Alternatively, for the solution of $1 \mathrm{c}$ and 4, the terminal region was clearly detected (Figure 4c). Changes over time in the oscillatory shear moduli are summarized in Supplementary Figures S1-S3.

We found a remarkable change in the dynamic viscoelastic property when the tetratopic crosslinker $\mathbf{5}$ was used in complexation with 1a. In a solution of $1 \mathrm{a}(19 \mathrm{~mm})$ and $5(52 \mathrm{~mm})$ stirred at $40{ }^{\circ} \mathrm{C}$, a stirring bar stopped on the 3rd day. The frequency dependence of the oscillatory shear moduli showed plateaus at low frequency, and indicated that a network structure had formed in the transparent solution (Figure 5a). ${ }^{33}$ Once formed, returning to a low viscosity solution required a 7-day shaking after triple dilution. Replacing the tetratopic 5 with the ditopic $4(0.10 \mathrm{M})$ in the above solution resulted in the value of $\eta_{0}$ lying on the order of $10^{0} \mathrm{~Pa} \bullet$, although almost the same amount of permethylated $\beta-C D$ was present in the solution (Table 2). In a solution of $1 \mathrm{c}(19 \mathrm{~mm})$ and $5(52 \mathrm{~mm})$ stirred at $40{ }^{\circ} \mathrm{C}$ for 3 days, the terminal region was found (Figure $5 b$ ), which was not detected when the ditopic $4(0.10 \mathrm{M})$ was used in place of $\mathbf{5}$ (Table 2$)$.

\section{CONCLUSIONS}

A series of dumbbell-shaped PEG chains 1 were designed and prepared to investigate systematically the role of barriers at the ends of 1 through the self-assembling of size-mismatched cyclic and linear components (pseudopolyrotaxane formation). Differences in chemical structure at the ends of a chain were projected on macroscopic behaviors: substituents on 2,4-positions ( $\mathbf{a}, \mathbf{b}$ or $\mathbf{c}$ ) affected the rate and yield of precipitation in the complexation with native $\beta$-CD that forms hydrogen bonds, and the rates of assembly as well 
as dissociation in complexation with a ditopic/tetratopic supramolecular crosslinker $4 / 5$ that kinetically stabilizes the assembly without relying on hydrogen bonds. In addition, the self-assembling of 1a-c with $4 / 5$ was induced only at $40^{\circ} \mathrm{C}$ or higher, although a number of supramolecular assemblies dissociate on heating. ${ }^{1,29-32,34-38}$ Substituent(s) on 2- or 2,6-positions (d or e) were too small or bulky to work well. The system was also well modulated by crosslinking of a cyclic component, as demonstrated by combinations of $\mathbf{1 a}-\mathbf{c}$ and monotopic 3/ditopic 4 , or $\mathbf{1 a} / \mathbf{c}$ and ditopic $4 /$ tetratopic 5 . A precise design of end groups according to a cyclic component would broaden the range of possibilities in selecting a chain without relying on a specific interaction between the components.

\section{ACKNOWLEDGEMENTS}

We thank Associate Professor Akio Ohta (Kanazawa University) and Dr Issey Osaka (JAIST) for their help in characterization (elemental analysis and mass spectrometry) of the new compounds.

1 Harada, A. \& Kamachi, M. Complex formation between poly(ethylene glycol) and $\alpha$ cyclodextrin. Macromolecules 23, 2821-2823 (1990)

2 Harada, A., Li, J. \& Kamachi, M. Preparation and properties of inclusion complexes of polyethylene glycol with $\alpha$-cyclodextrin. Macromolecules 26, 5698-5703 (1993).

3 Harada, A. \& Kamachi, M. Complex formation between cyclodextrin and poly(propylene glycol). J. Chem. Soc. Chem. Commun 19, 1322-1323 (1990).

4 Harada, A., Okada, M., Li, L. \& Kamachi, M. Preparation and characterization of inclusion complexes of poly(propylene glycol) with cyclodextrins. Macromolecules 28, 8406-8411 (1995).

5 Nepogodiev, S. A. \& Stoddart, J. F. Cyclodextrin-based catenanes and rotaxanes. Chem. Rev. 98, 1959-1976 (1998).

6 Wenz, G., Han, B. H. \& Müller, A. Cyclodextrin rotaxanes and polyrotaxanes. Chem. Rev. 106, 782-817 (2006)

7 Wenz, G. Recognition of monomers and polymers. Adv. Polym. Sci. 222, 1-54 (2009), and references therein.

8 Harada, A., Hashidzume, A., Yamaguchi, H. \& Takashima, Y. Polymeric rotaxanes. Chem. Rev. 109, 5974-6023 (2009).

9 Huang, F. \& Gibson, H. W. Polypseudorotaxanes and polyrotaxanes. Prog. Polym. Sci. 30, 982-1018 (2005).

10 Takata, T., Kihara, N. \& Furusho, Y. Polyrotaxanes and polycatenanes: recent advances in syntheses and applications of polymers comprising of interlocked structures. Adv. Polym. Sci. 171, 1-76 (2004).

11 Nakazono, K., Takashima, T., Arai, T., Koyama, Y. \& Takata, T. High-yield one-pot synthesis of permethylated $\alpha$-cyclodextrin-based polyrotaxane in hydrocarbon solvent through an efficient heterogeneous reaction. Macromolecules 43, 691-696 (2010)

12 Arai, T., Hayashi, M., Takagi, N. \& Takata, T. One-pot synthesis of native and permethylated $\alpha$-cyclodextrin-containing polyrotaxanes in water. Macromolecules 42 , 1881-1887 (2009).

13 Li, J., Harada, A. \& Kamachi, M. Sol-gel transition during inclusion complex formation between $\alpha$-cyclodextrin and high molecular weight poly(ethylene glycol)s in aqueous solution. Polym. J. 26, 1019-1026 (1994).

14 Gong, C. \& Gibson, H. W. Supramolecular chemistry with macromolecules: macromolecular knitting, reversible formation of branched polyrotaxanes by self-assembly. Macromol. Chem. Phys. 199, 1801-1806 (1998).

15 Sohgawa, Y. H., Fujimori, H., Shoji, J., Furusho, Y., Kihara, N. \& Takata, T. Polyslipping: a new approach to polyrotaxane-like assemblies. Chem. Lett. 30, 774-775 (2001).
16 Gibson, H. W., Yamaguchi, N. \& Jones, J. W. Supramolecular pseudorotaxane polymers from complementary pairs of homoditopic molecules. J. Am. Chem. Soc. 125, 3522 3533 (2003).

17 Katoono, R., Kobayashi, Y., Yamaguchi, M. \& Yui, N. Heat-induced supramolecular crosslinking of dumbbell-shaped PEG with $\beta-C D$ dimer based on reversible loose-fit rotaxanation. Macromol. Chem. Phys. 212, 211-215 (2011).

18 Katoono, R., Kobayashi, Y. \& Yui, N. Preparation of loose-fit polyrotaxane composed of $\beta$-cyclodextrin and poly(ethylene glycol) derivatives through the slipping-expanding protocol. Chem. Lett. 39, 892-893 (2010).

19 Udachin, K. A., Wilson, L. D. \& Ripmeester, J. A. Solid polyrotaxanes of polyethylene glycol and cyclodextrins: the single crystal X-ray structure of PEG $\beta$-cyclodextrin. J. Am. Chem. Soc. 122, 12375-12376 (2000).

20 Muderawan, I. W., Ong, T. T., Lee, T. C., Young, D. J., Ching, C. B. \& Ng, S. C. A reliable synthesis of 2 - and 6 -amino- $\beta$-cyclodextrin and permethylated- $\beta$-cyclodextrin. Tetrahedron Lett. 46, 7905-7907 (2005).

21 Zhang, G., Fang, L., Zhu, L., Sun, D. \& Wang, P. G. Syntheses and biological activity of bisdaunorubicins. Bioorg. Med. Chem. 14, 426-434 (2006).

22 Harada, A., Li, J. \& Kamachi, M. Preparation and characterization of a polyrotaxane consisting of monodisperse poly(ethylene glycol) and $\alpha$-cyclodextrins. J. Am. Chem. Soc. 116, 3192-3196 (1994).

23 Rostovtsev, V. V., Green, L. G., Fokin, V. V. \& Sharpless, K. B. A Stepwise huisgen cycloaddition process: copper(I)-catalyzed regioselective "ligation" of azides and terminal alkynes. Angew. Chem. Int. Ed. 41, 2596-2599 (2002).

24 Rodionov, V. O., Fokin, V. V. \& Finn, M. G. Mechanism of the ligand-free cui-catalyzed azide-alkyne cycloaddition reaction. Angew. Chem. Int. Ed. 44, 2210-2215 (2005).

25 Saenger, W. Cyclodextrin inclusion compounds in research and industry. Angew. Chem. Int. Ed. 19, 344-362 (1980).

26 Harada, A., Li, J., Suzuki, S. \& Kamachi, M. Complex formation between polyisobutylene and cyclodextrins: inversion of chain-length selectivity between $\beta$-cyclodextrin and $\gamma$-cyclodextrin. Macromolecules 26, 5267-5268 (1993).

27 Harada, A., Li, J. \& Kamachi, M. The molecular necklace: a rotaxane containing many threaded $\alpha$-cyclodextrins. Nature 356, 325-327 (1992).

28 Ferry, J. D. Viscoelastic Properties of Polymers Ch. 11, 264-320 (John Wiley \& Sons Inc., New York, 1980).

29 Sandier, A., Brown, W. \& Mays, H. Interaction between an adamantane end-capped poly(ethylene oxide) and a $\beta$-cyclodextrin polymer. Langmuir 16, 1634-1642 (2000).

30 van de Manakker, F., van der Pot, M., Vermonden, T., van Nostrum, C. F. \& Hennink, W. E. Self-assembling hydrogels based on $\beta$-cyclodextrin/cholesterol inclusion complexes. Macromolecules 41, 1766-1773 (2008).

31 Herbst, F., Schröter, K., Gunkel, I., Gröger, S., Albrecht, T. T., Balbach, J. H. \& Binder, W. Aggregation and chain dynamics in supramolecular polymers by dynamic rheology: cluster formation and self-aggregation. Macromolecules 43, 10006-10016 (2010).

32 Dingenouts, N., Klyatskaya, S., Rosenfeldt, S., Ballauff, M. \& Höger, S. Temperatureinduced switching between aggregated and nonaggregated states in coilringcoil block copolymers. Macromolecules 42, 5900-5902 (2009).

33 Larson, R. G. The Structure and Rheology of Complex Fluids (ed. Gubbins, K.E.) Ch. 5, 232-260 (Oxford University Press, New York, 1999).

34 Brunsveld, L., Folmer, B. J. B., Meijer, E. W. \& Sijbesma, R. P. Supramolecular polymers. Chem. Rev. 101, 4071-4097 (2001).

35 Borzsonyi, G., Beingessner, R. L., Yamazaki, T., Cho, J. Y., Myles, A. J., Malac, M., Egerton, R., Kawasaki, M., Ishizuka, K., Kovalenko, A. \& Fenniri, H. Water-soluble J-type rosette nanotubes with giant molar ellipticity. J. Am. Chem. Soc. 132, 15136-15139 (2010).

36 Nieuwenhuizen, M. M. L., de Greef, T. F. A., van der Bruggen, R. L. J., Paulusse, J. M. J., Appel, W. P. J., Smulders, M. M. J., Sijbesma, R. P. \& Meijer, E. W. Self-assembly of ureido-pyrimidinone dimers into one-dimensional stacks by lateral hydrogen bonding. Chem. Eur. J. 16, 1601-1612 (2010).

37 George, S. J. \& Ajayaghosh, A. Self-assembled nanotapes of oligo(p-phenylene vinylene)s: sol-gel-controlled optical properties in fluorescent $\pi$-electronic gels. Chem. Eur. J. 11, 3217-3227 (2005).

38 Ikeda, M., Nobori, T., Schmutz, M. \& Lehn, J. M. Hierarchical self-assembly of a bowshaped molecule bearing self-complementary hydrogen bonding sites into extended supramolecular assemblies. Chem. Eur. J. 11, 662-668 (2005).

Supplementary Information accompanies the paper on Polymer Journal website (http://www.nature.com/pj) 